\title{
Hip and trunk muscles activity during nordic hamstring exercise
}

\author{
Shideh Narouei', Atsushi Imai ${ }^{2}$, Hiroshi Akuzawa ${ }^{2}$, Kiyotaka Hasebe ${ }^{2}$, Koji Kaneoka ${ }^{3, *}$ \\ ${ }^{1}$ Tehran University, School of Sport medicine Sciences, Tehran, Iran \\ ${ }^{2}$ Waseda University, School of Sport Sciences, Tokorozawa, Japan \\ ${ }^{3}$ Waseda University, Faculty of Sport Sciences, Tokorozawa, Japan
}

The nordic hamstring exercise (NHE) is a dynamic lengthening hamstring exercise that requires trunk and hip muscles activation. Thigh muscles activation, specifically hamstring/quadriceps contractions has been previously examined during NHE. Trunk and hip muscles activity have not been enough studied. The aim of this study was to analyze of hip and trunk muscles activity during NHE. Surface electromyography (EMG) and kinematic data were collected during NHE. Ten healthy men with the age range of 21-36 years performed two sets of two repetitions with downward and upward motions each of NHE. EMG activity of fifteen trunk and hip muscles and knee kinematic data were collected. Muscle activity levels were calculated through repeated measure analysis of variance in downward and upward motions, through Paired t-test between downward and upward motions and gluteus maximus to erector spine activity ratio (Gmax/ES ratio) using Pearson correlation analyses were evaluated. Semitendinosus and biceps femoris muscles activity levels were the greatest in both motions and back extensors and internal oblique muscles activity were greater than other muscles $(P<0.05)$. The decreased Gmax/ES ratio was significantly related to peak knee extension angle in downward $(r=0.687)$ and upward motions $(r=0.753)(P<0.05)$. These findings indicate the importance of synergistic muscles and trunk muscles coactivation in eccentric and concentric hamstrings contractions. It could be important for early assessment of subjects with hamstring injury risk.

Keywords: Electromyography, Nordic hamstring exercise, Muscle activity, Peak knee extension angle

\section{INTRODUCTION}

Hamstring muscle strains are often observed in sprinting and jumping activities (Woods et al., 2004). The incidence of hamstring strain is $12 \%-16 \%$ of all injuries and $54.4 \%$ of all muscle strains in athletes (Eirale et al., 2013; Ekstrand et al., 2011). Risk factors of hamstring strains include: previous hamstring injury, improper warm up, core muscles weakness, fatigue, low coordination of trunk and pelvic muscles strength, lumbar posture abnormality and imbalance between muscles strength ratio (Cameron et al., 2009; Schmitt et al., 2012; Sherry and Best, 2004; Yeung et al., 2009).

Hamstring injuries often occur with extreme stretch in simultaneous hip flexion and knee extension during eccentric contractions (Askling et al., 2007). Also, rapid change of hamstring con- traction from eccentric to concentric can cause hamstring injuries (Woods et al., 2004). Eighty percent hamstring strains occur in long head of biceps femoris (BF) during terminal swing, hence conception of causes and hamstring injury prevention is important for athletic society (Chumanov et al., 2007; Koulouris and Connell, 2003).

Long head of BF and gluteus maximus (Gmax) stabilize pelvis (Leinonen et al., 2000) and Gmax keeps upright position in standing (Jenkins and Hollinshead, 1998). Similarly, erector spine (ES) muscles keep trunk erect posture during high speed running (Sado et al., 2016) and internal oblique (IO) muscles activity decreases stretch on BF (Devlin, 2000). Sagittal plane movements of pelvis and hip in subjects with previous hamstring injury are asymmetry (Daly et al., 2016). Furthermore, the synergist muscle weakness on the same joint increases activity demands compared
${ }^{*}$ Corresponding author: Koji Kaneoka (iD https://orcid.org/0000-0002-4993-7772 Department of Sport \& Health Science, Waseda University, Faculty of Sport Sciences, 1-104 Totsukamachi, Shinjuku-ku, Tokyo, 169-8050, Japan Tel: +81-429476855, Fax: +81-429476855, E-mail: kaneoka@waseda.jp Received: December 19, 2017 / Accepted: February 12, 2018
This is an Open Access article distributed under the terms of the Creative Commons Attribution Non-Commercial License (http://creativecommons.org/licenses/by-nc/4.0/) which permits unrestricted non-commercial use, distribution, and reproduction in any medium, provided the original work is properly cited. 
to other synergists, then muscle strain may occur (Sahrmann, 2002). Gmax and ES activity as trunk extensor synergists changes Gmax to ES activity ratio (Gmax/ES ratio) (Kim and Yoo, 2016). Also, the decreased Gmax activity relative to semitendinosus (ST) muscle was related to increased ipsilateral ES activity (Tateuchi et al., 2012).

The nordic hamstring exercise (NHE) is a progressive eccentric exercise that is simulated a condition with high muscle force demand during knee extension (Iga et al., 2012). This task reduced the incidence rate of primary hamstring injuries to 60\% (Thorborg, 2012). Hamstring activation on two joints during NHE increases effectively maximal eccentric hamstring strength more than traditional exercises (Mjølsnes et al., 2004). The chronicity of agonist/antagonist imbalances has the important role in occurrence of recurrent hamstring injuries (Croisier et al., 2002; Croisier, 2004). In previous studies the preventive and treatment methods have been examined only in chronic stage of hamstring strains (Croisier et al., 2002). Hence, rehabilitation exercise programs must be individually planned for preventing of recurrence chronic injuries (Croisier, 2004).

The impairment of abdominal, Gmax and rectus femoris (RF) muscles action can make overuse syndrome of hamstring muscles, too (Sahrmann, 2002). Thus, it is very helpful for injury prevention to find how other muscles on hip and knee joints act (Sahrmann, 2002). Change in knee joint angle from flexion to extension increases abdominal muscles activity to control of trunk (Eom et al., 2016). Furthermore, antagonistic cocontraction of trunk muscles provides mechanical stability of lumbar spine in neutral postures (Cholewicki et al., 1997). Therefore the increased spinal loads increase abdominal and back muscle cocontractions (Granata and Marras, 2000). Hip and core stability provides a stable base for lower extremities movements (Willson et al., 2005). Likewise, proper function of anterior and posterior trunk and hip muscles in sagittal plane is necessary for core stability (Willson et al., 2005). Therefore, core dysfunction increases the risk of lower extremity injuries (Willson et al., 2005).

In previous investigations have not been shown trunk and hip muscles activity levels during hamstring contractions and there was a lack of study about the role of hip and trunk muscles during NHE. Also, some studies were concentrated on hamstring/quadriceps muscle activity ratio ( $\mathrm{H} / \mathrm{Q}$ ratio) but there wasn't any study about Gmax/ES ratio during NHE.

The main purpose of this study was to analyze of hip and trunk muscles activity during NHE. We hypothesized that trunk muscles activity level would increase and Gmax/ES ratio would de- crease with increasing peak knee extension angle during NHE.

\section{MATERIALS AND METHODS}

\section{Subjects}

Ten healthy men (age, $26.1 \pm 5.46$ years; height, $172.9 \pm 6.57 \mathrm{~cm}$; weight, $60.7 \pm 5.79 \mathrm{~kg}$; body mass index, $\left.20.32 \pm 1.53 \mathrm{~kg} / \mathrm{m}^{2}\right)$; participated in this study. If the subjects had neuromuscular, cardiovascular disease and hamstring injury during the previous 6 months, they were excluded from this study. Ethical approval was obtained from Waseda University.

\section{Experimental protocol}

Prior to measurements, the subjects were instructed how to accomplish the NHE. The starting position of NHE was kneeling with upright state of trunk over a mat on the ground, knees flexed $90^{\circ}$ and both arms placed in front of the body. A cooperator was holding lower legs of the subject to support. The participants lowered whole of trunk toward the ground as far as possible without bending or rotating in hip joint or trunk while keeping neutral posture in trunk and hip joints. The participants were allowed to incline until maximum downward moving point. When the participants reached the maximum point they returned back to the starting position without changing in straight status of the body. They performed this NHE movement two repetitions in a row with 2-min resting time between trails and two sets of the task. A metronome was set at 60 beats per minute to define the movement speed. Participants leaned forward as much as they could for $3 \mathrm{sec}$ and came back to start position for another $3 \mathrm{sec}$. Participants performed NHE twice in a row then 2-min resting time was allocated between trials. Manual resistance was applied for each muscle to obtain maximal voluntary isometric contractions (MVICs) for 3 sec after NHE trials.

\section{Electromyography and kinematics measurements}

We examined electromyography (EMG) characteristics of fifteen muscles. The muscles in right $(\mathrm{Rt})$ side of body were included: BF, ST, Gmax, gluteus medius (Gmed), RF and in Rt and left (Lt) sides of body: IO, external oblique (EO), rectus abdominis (RA), multifidus (MF), and ES. After shaving and cleaning the skin with alcohol, we used bipolar surface $\mathrm{Ag} / \mathrm{Agcl}$ electrodes (Blue sensor N-00-S, METS Co., Tokyo, Japan). The diameter of surface electrodes was $8 \mathrm{~mm}$ and interelectrode distance was 20 $\mathrm{mm}$. A wireless EMG telemeter system (Biolog DL-5000, S \& ME Co., Tokyo, Japan) were used to examine muscle activities. 
Location of muscles was confirmed with palpation of the landmarks and isometric muscle contractions. The electrodes placement on both side of spine was for ES; $2 \mathrm{~cm}$ lateral of the $3 \mathrm{rd}$ lumbar spinous process and MF; at level of 5 th lumbar spinous process on a line extending from posterior superior iliac spine to first lumbar vertebra. The electrode placement was for Gmax; the midpoint between greater trochanter and sacrum and Gmed; the midpoint between iliac crest and greater trochanter of femur. Also, the electrodes were placed for ST; the midpoint between ischial tuberosity and medial epicondyle of tibia, RF; the midpoint between anterior superior iliac spine and superior edge of patella, and BF; the midpoint between ischial tuberosity and lateral epicondyle of tibia. For abdominal muscles, along the fibers electrodes placement were for $\mathrm{IO} ; 2 \mathrm{~cm}$ medial side of anterior superior iliac spine, EO; $15 \mathrm{~cm}$ lateral side of umbilicus and RA; $3 \mathrm{~cm}$ lateral side of umbilicus (Hermens et al., 2000).

Kinematic data were recorded using 8 motion capture cameras (Oqus, Qualysis Ltd., Co., Goteborg, Swedish). The reflective markers were placed in Rt side of body on greater trochanter, lateral condyle of femur and lateral malleolus. The knee joint angle was defined between the lateral condyle of femur and along of thigh and shank. The knee joint angle was calculated as motion of the thigh relative to shank using the reflective markers of motion capture cameras. Also, peak knee angle for each subject was calculated by subtracting the angle between thigh and shank where the subject could incline maximally downward (the peak knee extension angle) from the $90^{\circ}$ angle at starting position.

\section{Data analysis}

The sampling rate of EMG was $1,000 \mathrm{~Hz}$ and it was $200 \mathrm{~Hz}$ for motion system. Raw EMG signals were analyzed with software (BIMUTAS-Video, Kissei Comtec Co., Ltd., Nagano, Japan). The EMG data were rectified, high-pass filtered at $20 \mathrm{~Hz}$, and low-pass filtered at $500 \mathrm{~Hz}$ to remove the artifacts. The 2-dimensional angles of knee in sagittal plane and muscles activity were the dependent variables. A trigger mechanism was used to synchronize the EMG measurements and the motion capture system data.

In this study, NHE was included downward and upward motions. Downward motion was defined as forward movement from starting position or kneeling toward ground until maximum knee extension angle that each subject could achieve with knee extending. Upward motion was defined as backward movement while knee flexing from maximum knee extension angle toward starting position. The muscles activity levels were measured in 1 sec before maximum knee extension angle during downward motion and in $1 \mathrm{sec}$ after maximum knee extension angle during upward motion. Therefore the onset of motion in downward motion was from kneeling with the point defined between the markers on greater trochanter, lateral femoral condyle and lateral malleolus and the end of motion was where the participants could move maximally downward (peak knee angle). Also in upward motion, the onset of motion was reversely from the peak knee angle and the end of motion was kneeling. The root mean square (RMS) values of each muscle over $1 \mathrm{sec}$ in downward and upward motions were normalized by RMS values of MVICs in each muscle to calculate \%MVIC. The EMG signals were designated less than $10 \%$ MVICs to reduce probable signal changes with fatigue and the electrode displacement.

\section{Statistical analysis}

The data were analyzed in SPSS ver. 17.0 (SPSS Inc., Chicago, IL, USA). We used the parametric statistical methods because all data had a normal distribution confirmed by using KolmogorovSmirnov test. We analyzed muscles activity using repeated measure analysis of variance to compare muscle activity levels in downward and upward motions, separately. Also, we compared muscle activity levels with paired $t$-test between downward and upward motions. Statistical significance was determined as $P<0.05$ for all statistical tests. We used Pearson correlation to determine relation between Gmax/Es activity ratios and peak knee extension angle. We calculated Gmax/ES ratio in downward and upward motions. Also, we examined the correlation between Gmax/ES ratio and peak knee extension angle in both motions during NHE.

\section{RESULTS}

The results of Mean and standard deviation of muscles activity levels in downward and upward motions during NHE are presented in (Table 1, Fig. 1). Mean EMG activity level of ST muscle in downward and upward motions during NHE was the greatest of all muscles and BF activity level was the second greatest $(P<$ 0.05) (Table 1). Considerably, ES and MF muscles activity levels were greater than other muscles after hamstring muscle activity. Also, IO and EO muscles activity levels were greater than other trunk muscles after ES and MF muscles, respectively $(P<0.05)$.

There were significant differences in RtIO, RtGmax, RtMF, and ES muscle activity levels between downward and upward motions during NHE $(P<0.05)$ (Fig. 1). Therefore, RtIO, RtG- 
Table 1. The muscles activity levels in downward and upward motions during NHE

\begin{tabular}{|c|c|c|}
\hline Muscle & Downward motion & Upward motion ${ }^{\text {b) }}$ \\
\hline RtlO & $21.71 \pm 10.27^{*}$ & $25.22 \pm 10.48$ \\
\hline Lt|O & $26.09 \pm 11.42$ & $25.93 \pm 9.45$ \\
\hline RtEO & $16.44 \pm 17.93$ & $18.68 \pm 20.08$ \\
\hline LtEO & $9.44 \pm 5.94$ & $9.71 \pm 5.81$ \\
\hline RtRA & $1.89 \pm 1.05$ & $2.23 \pm 1.34$ \\
\hline LtRA & $2.32 \pm 1.69$ & $2.36 \pm 1.83$ \\
\hline RtMF & $32.84 \pm 12.70$ & $37.28 \pm 10.03$ \\
\hline LtMF & $36.70 \pm 15.15$ & $37.59 \pm 14.34$ \\
\hline RtES & $36.28 \pm 13.70$ & $38.52 \pm 8.79$ \\
\hline LtES & $32.87 \pm 11.47$ & $36.36 \pm 7.44$ \\
\hline RtGmax & $7.66 \pm 4.99$ & $9.08 \pm 5.45$ \\
\hline RtBF & $61.68 \pm 48.29$ & $61.20 \pm 38.02$ \\
\hline RtST & $71.09 \pm 23.35$ & $72.18 \pm 20.39$ \\
\hline RtRF & $3.11 \pm 0.78$ & $3.06 \pm 0.84$ \\
\hline RtGmed & $23.76 \pm 16.19$ & $26.81 \pm 18.69$ \\
\hline
\end{tabular}

Values are presented as mean \pm standard deviation (mv).

NHE, nordic hamstring exercise; downward motion, 1 sec before peak knee angle of NHE; upward motion, 1 sec after peak knee angle of NHE; RtIO, right internal oblique; LtIO, left internal oblique; RtEO, right external oblique; LtEO, left external oblique; RtRA, right rectus abdominis; LtRA, left rectus abdominis; RtMF, right multifidus; LtMF, left multifidus; RtES, right erector spine; LtES, left erector spine; RtGmax, right gluteus maximus; RtBF, right biceps femoris; RtST, right semitendinosus; $\mathrm{RtRF}$, right rectus femoris; $\mathrm{Rt} G$ med, right gluteus medius. ${ }^{*} P<0.05$.

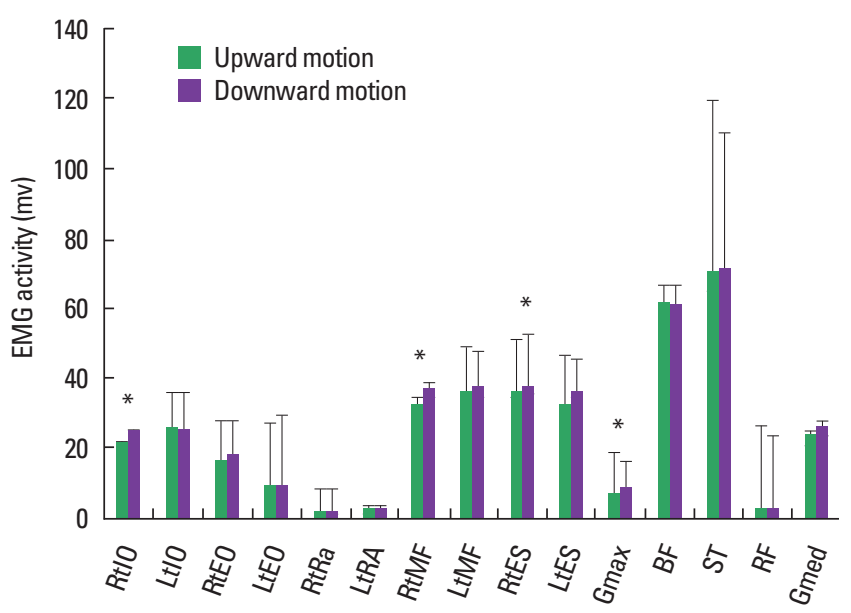

Fig. 1. Mean \pm standard deviation of muscle activities in downward and upward motions during NHE. NHE, nordic hamstring exercise; EMG, electromyography; RtIO, right internal oblique; LtIO, left internal oblique; RtEO, right external oblique; LtEO, left external oblique; RtRA, right rectus abdominis; LtRA, left rectus abdominis; RtMF, right multifidus; LtMF, left multifidus; RtES, right erector spine; LtES, left erector spine; Gmax, gluteus maximus; BF, biceps femoris; ST, semitendinosus; RF, rectus femoris; Gmed, gluteus medius; downward motion, 1 sec before peak knee angle of NHE; upward motion, 1 sec after peak knee angle of NHE. ${ }^{*} P<0.05$. max, RtMF, and ES muscle activity levels during upward motions were significantly greater than those in downward motion. The mean difference of RtMF activity level between two motions was greater than other muscles activity levels $(P<0.05)$. Mean peak knee angle was $72.87 \pm 6.70$ for all subjects during NHE.

The EMG muscles activity levels in downward motion during NHE are shown in (Fig. 2). RtIO and LtIO muscle activity levels were more than RtRA, LtRA, and RtRF muscle activity levels $(P<0.05)$. Also RtMF, LtMF, RtES, and LtES muscle activity levels were more than LtEO, RtRA, and LRA muscle activities $(P<0.05)$. MF and ES muscle activity levels in both sides were more than RtGmax and RtRF muscle activities $(P<0.05)$. LtIO muscle activity level was more than RtRF muscle activity $(P<0.05)$ (Fig. 2).

Also, the EMG muscle activity levels in upward motion are shown in (Fig. 3). RtIO and LtIO muscle activity levels were more than RtRA, LtRA, RtRF, and RtIO muscle activity level was more than RtGmax in upward motion $(P<0.05)$. RtMF and LtMF and ES muscle activity levels were more than LtEO, RtRA, and LtRA muscle activity levels $(P<0.05)$. Therefore, IO, ES, and MF muscle activity levels were significantly increased after hamstring activity in both upward and downward motions $(P<0.05)$ (Figs. 2, 3). Gmax/ES activity ratio was $0.22 \pm 0.11$ in downward motion and $0.24 \pm 0.13$ in upward motion. A significant negative

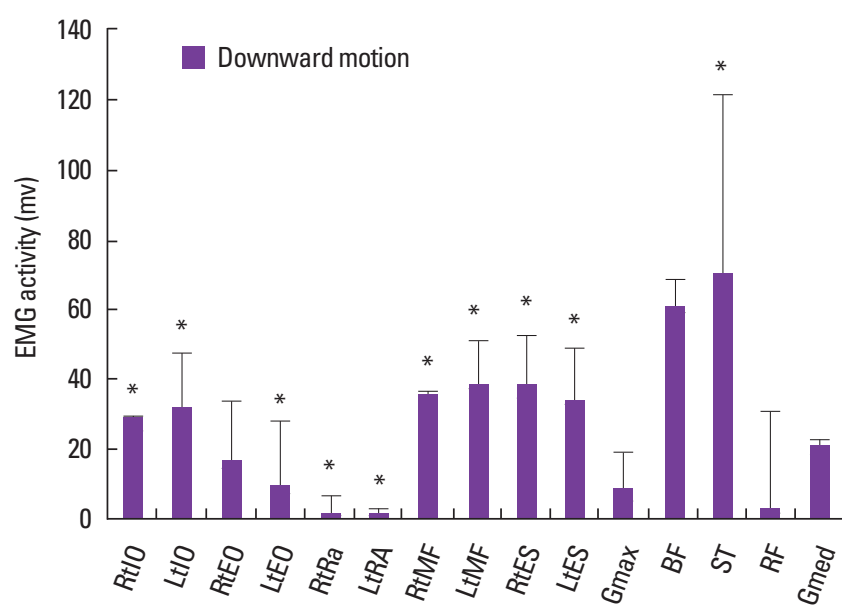

Fig. 2. Mean \pm standard deviation of muscle activities in downward motion during NHE. NHE, nordic hamstring exercise; EMG, electromyography; RtIO, right internal oblique; LtIO, left internal oblique; RtEO, right external oblique; LtEO, left external oblique; RtRA, right rectus abdominis; LtRA, left rectus abdominis; RtMF, right multifidus; LtMF, left multifidus; RtES, right erector spine; LtES, left erector spine; Gmax, gluteus maximus; BF, biceps femoris; ST, semitendinosus; RF, rectus femoris; Gmed, gluteus medius; downward motion, 1 sec before peak knee angle of NHE. ${ }^{*} P<0.05$. 


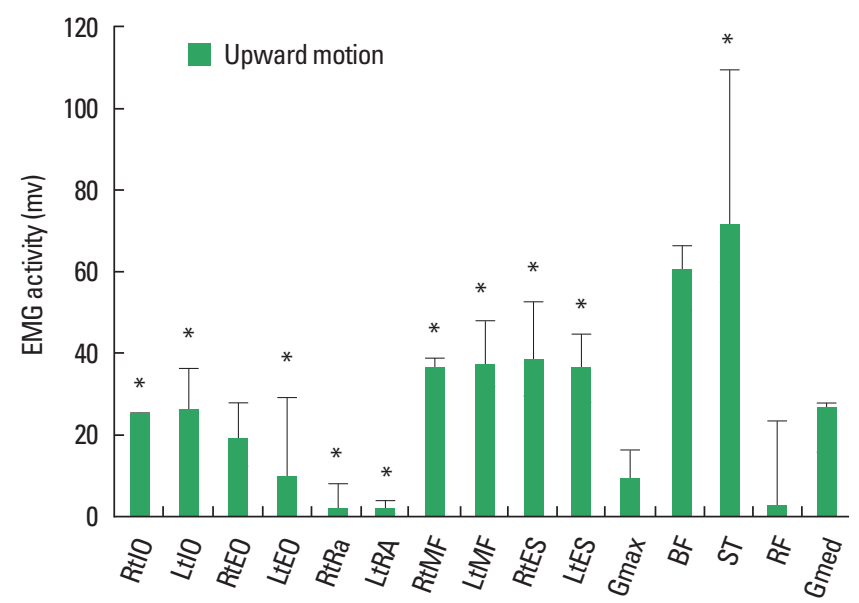

Fig. 3. Mean \pm standard deviation of muscle activities in upward motion during NHE. NHE, nordic hamstring exercise; EMG, electromyography; RtIO, right internal oblique; LtIO, left internal oblique; RtEO, right external oblique; LtEO, left external oblique; RtRA, right rectus abdominis; LtRA, left rectus abdominis; RtMF, right multifidus; LtMF, left multifidus; RtES, right erector spine; LtES, left erector spine; Gmax, gluteus maximus; BF, biceps femoris; ST, semitendinosus; $\mathrm{RF}$, rectus femoris; Gmed, gluteus medius; upward motion, 1 sec after peak knee angle of NHE. ${ }^{*} P<0.05$.

linear correlation was found between Gmax/ES ratio and peak knee angle in downward $(r=0.687, P=0.028)$ and upward motions $(r=0.753, P=0.012)$, respectively (Fig. 4).

\section{DISCUSSION}

This study is the first analysis of low back, abdominal, hip, and hamstring muscles activity in both downward and upward motions during NHE. The highlight finding of this study was that ST muscle activity level was the highest among the muscles during downward and upward motions. Also, trunk muscles activity level especially back extensor (ES) and oblique muscles (IO) was increased and Gmax/ES ratio decreased with increasing knee extension angle during NHE.

The NHE improves eccentric hamstring muscle strength (Delahunt et al., 2016). Eccentric contractions have been used clinically for hamstring strain prevention in athletes (Murphy et al., 2012; Orchard et al., 2013). Although several studies have examined hamstring muscle activity, the assessment of hip and trunk muscles activity was necessary during NHE. We concur the researchers that ST muscle is preferably activated during NHE (Bourne et al., 2016) and confirm the results of (Ditroilo et al., 2013) that BF activity during NHE was very high.

The kinematic and neuromuscular analyses can achieve beneficial issues for coaches and athletes of sport medicine in hamstring
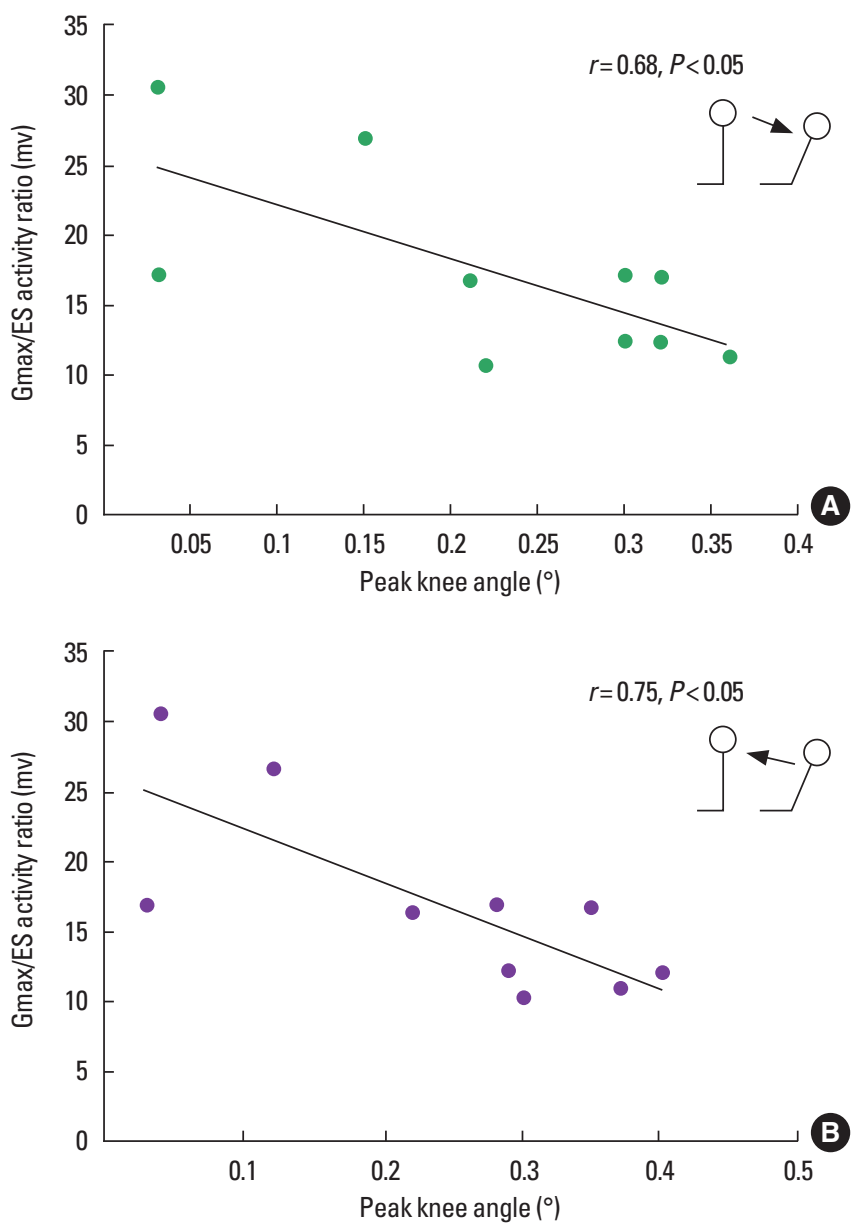

Fig. 4. Linear negative relationships between the decreased Gmax/ES ratio and the increased peak knee angle in downward $(A)$ and upward motions $(B)$. Correlation coefficient $(r)$ and significant level $(P<0.05)$ are noted. ES, erector spine; Gmax/ES activity ratio, gluteus maximus to erector spine activity ratio; $\mathrm{NHE}$, nordic hamstring exercise; downward motion, 1 sec before peak knee angle of NHE; upward motion, 1 sec after peak knee angle of NHE.

injury prevention (Brukner, 2015). Other studies estimated that $\mathrm{BF}$ muscle was activated more than other hamstrings in eccentric contraction (Higashihara et al., 2010; Woodley and Mercer, 2005), but in our study ST muscle activity level was the highest during NHE. According to our results, MF and ES muscles activity level after hamstring activity level were more than other muscles in downward and upward motions. Trunk muscles attached to pelvis and control the pelvis tilts and length changes of hamstring muscle. These muscles provide the proper condition for optimal hamstring contraction and prevent injury in high speed sports (Jull and Richardson, 1994; Sherry and Best, 2004; Wohlfahrt et al., 1993).

Isometric ES muscle contraction is necessary for optimal stand- 
ing position (Boucher et al., 2013). Moreover abdominal and hip extensor muscles with posterior pelvis tilting and back extensor and hip flexors with anterior tilting contribute to force couples for spinal stability (Sahrmann, 2002). Thus coactivation of force couples is an important factor in maintaining neutral pelvis tilt and lumbar lordosis (Granata and Marras, 2000; Jull and Richardson, 1994). Consequently, posterior hip and trunk muscles with central of gravity displacement activate in NHE and these muscles with isometric contractions as antigravity muscles are responsible for keeping erect posture.

Furthermore, isometric abdominal contractions keep erect position of spine during NHE. Inferomedial fibers of IO muscles with force closure mechanism contribute to sacroiliac joint control (Snijders et al., 1995). Also, IO muscles neutralize the pelvis tilts that gravity force creates (Snijders et al., 1998). Regarding previous studies, IO muscle activates greater than EO against gravity in trunk erect position (Snijders et al., 1995; Vleeming et al., 1997) and IO muscle keeps pelvis stability during lower limb movement (Floyd and Silver, 1950). Consequently, trunk muscles coactivate to keep Rt position of spine during eccentric and concentric contractions of hamstrings (Sahrmann, 2002). The researchers showed that imbalances of core muscles caused pelvis instability as hamstring strains will occur during eccentric contractions (Chumanov et al., 2007). Vleeming et al. (1997) and Snijders et al. (1995) showed that oblique abdominal muscles in trunk erect position have greater activity level against gravity relative to Gmax, ES and BF.

In our results, IO muscles activity levels after hamstring and back extensor muscles activity were more than other muscles activity in both downward and upward motions during NHE. Thus, MF, ES and oblique abdominal muscles create sufficient stability in trunk and pelvis and these muscles cause a proper performance basis for hamstring muscles during NHE. In other words, when MF, ES and abdominal muscles activate greater, reciprocally, eccentric and concentric hamstring contractions will be better. The results of this study highlighted the role of IO and ES muscles during hamstring eccentric and concentric contractions. Sherry and Best (2004) presented that trunk stabilization exercises can prevent hamstring strains in athletes. Therefore we conclude that IO, ES and MF strengthening can affect hamstring contractions improvement. These results are very important in design of injury preventive protocols for athletes with more risk of hamstring injury, especially soccer players and runners (Murphy et al., 2012).

Furthermore, we found that Gmax/ES ratio had a negative cor- relation with knee extension angle during NHE. Gmax activity level decreased significantly with increasing knee extension angle relative to ES activity. In other words, whatever knee extension angle increased, the demand of ES activity was more than Gmax. Guilhem et al. (2014) showed linear correlations between the EMG activity (RMS) and isometric peak torque of ES muscles. Also Sado et al. (2016) showed that hip extension torque and posterior pelvis tilt increase during sprinting in stance limb. ES muscles activate to keep trunk erect posture and neutralize the posterior pelvis tilt and lumbar flexion with increasing lumbosacral extension torque during high speed running (Sado et al., 2016). When the participants inclined downward in NHE, ES muscles activated to counteract the hip extension torque. Moreover, regarding to decrease the distance of ES to ground, ES activated to keep trunk erect posture versus gravitational force and hip extension torque more than Gmax. Similarly, Gmax/ES ratio increased with decreasing knee extension angle in upward motion. In other words, the demand of ES activity with decreasing knee extension and returning to kneeling decreased.

In summary, these results emphasized that the high activity level of ES muscles during eccentric and concentric hamstring contractions is very necessary. However, sufficient contractions of both ES and Gmax are important for pelvis stabilization and proper hamstring performance. Thus, the assessment of $\mathrm{Gmax} / \mathrm{ES}$ ratio during NHE and strengthening of ES and Gmax muscles can be very important in rehabilitation of muscle imbalances and hamstring injury preventive methods. Also, if each Gmax or ES muscle activate inefficiently, the hamstrings activity may increase compensatory. This explains the synergistic cooperation between Gmax, ES and hamstring muscles in closed kinematic chain of lower limb as other studies (Leinonen et al., 2000; Nelson-Wong et al., 2012). Unlike another studies, $\mathrm{H} / \mathrm{Q}$ ratio wasn't decreased in our results, because all our participants were healthy. Also, we did not found other significant muscle ratios in this study. We recommend more studies about muscle interactions and activity ratios.

There were some limitations to this study. We did not examine the effect of movement velocity and the effect of velocity on muscles activity in this study. Some previous studies were demonstrated that the extent of peak hip and knee angles in different velocities was various (Chumanov et al., 2011; Kuitunen et al., 2002; Thelen et al., 2005). Also they concluded that abdominal oblique muscles activity causes to reduce hamstring stretches in different velocities, therefore we suggest that further studies are necessary (Chumanov et al., 2011; Kuitunen et al., 2002; Thelen et al., 
2005).

All subjects in this study were healthy and did not have any hamstring injury. Our results as the first step for assessment of hip and trunk muscles performance during hamstring eccentric and concentric contractions are sufficed only. Hence future researches about comparison of relationship between trunk and hip muscles performance in healthy and injured subjects during NHE would be needed.

In conclusion, neuromuscular analysis of NHE demonstrated that high increased ST and BF activity levels in eccentric and concentric contractions compared to other muscles during NHE. Furthermore, increased activity of ES and oblique muscles (IO) and decreased $\mathrm{Gmax} / \mathrm{ES}$ ratio was related to increased knee extension angle. We recommend that hamstring injury preventive programs and comprehensive rehabilitation after emphasis on hamstring muscles strengthening will be concentrated on trunk and hip muscles.

\section{CONFLICT OF INTEREST}

No potential conflict of interest relevant to this article was reported.

\section{ACKNOWLEDGMENTS}

The authors would like to thank Dr. Yu Okubo, Mr. Satoshi Izuka, Ms. Yuiko Matsuura, Mr. Naoto Matsunaga, Mr. Tomukon Oshikawa for their assistance with data collection and all participants for their recruitment.

\section{REFERENCES}

Askling CM, Tengvar M, Saartok T, Thorstensson A. Acute first-time hamstring strains during slow-speed stretching: clinical, magnetic resonance imaging, and recovery characteristics. Am J Sports Med 2007;35:17161724.

Boucher JA, Normand MC, Descarreaux M. Trunk isometric force production parameters during erector spinae muscle vibration at different frequencies. J Neuroeng Rehabil 2013;10:89.

Bourne MN, Opar DA, Williams MD, Al Najjar A, Shield AJ. Muscle activation patterns in the Nordic hamstring exercise: Impact of prior strain injury. Scand J Med Sci Sports 2016;26:666-674.

Brukner P. Hamstring injuries: prevention and treatment-an update. Br J Sports Med 2015;49:1241-1244.

Cameron ML, Adams RD, Maher CG, Misson D. Effect of the HamSprint
Drills training programme on lower limb neuromuscular control in Australian football players. J Sci Med Sport 2009;12:24-30.

Cholewicki J, Panjabi MM, Khachatryan A. Stabilizing function of trunk flexor-extensor muscles around a neutral spine posture. Spine (Phila Pa 1976) 1997;22:2207-2212.

Chumanov ES, Heiderscheit BC, Thelen DG. Hamstring musculotendon dynamics during stance and swing phases of high-speed running. Med Sci Sports Exerc 2011;43:525-532.

Chumanov ES, Heiderscheit BC, Thelen DG. The effect of speed and influence of individual muscles on hamstring mechanics during the swing phase of sprinting. J Biomech 2007;40:3555-3562.

Croisier JL. Factors associated with recurrent hamstring injuries. Sports Med 2004;34:681-695.

Croisier JL, Forthomme B, Namurois MH, Vanderthommen M, Crielaard JM. Hamstring muscle strain recurrence and strength performance disorders. Am J Sports Med 2002;30:199-203.

Daly C, Persson UM, Twycross-Lewis R, Woledge RC, Morrissey D. The biomechanics of running in athletes with previous hamstring injury: a case-control study. Scand J Med Sci Sports 2016;26:413-420.

Delahunt E, McGroarty M, De Vito G, Ditroilo M. Nordic hamstring exercise training alters knee joint kinematics and hamstring activation patterns in young men. Eur J Appl Physiol 2016;116:663-672.

Devlin L. Recurrent posterior thigh symptoms detrimental to performance in rugby union: predisposing factors. Sports Med 2000;29:273-287.

Ditroilo M, De Vito G, Delahunt E. Kinematic and electromyographic analysis of the Nordic Hamstring Exercise. J Electromyogr Kinesiol 2013;23:1111-1118.

Eirale C, Farooq A, Bisciotti G, Chalabi H. How injuries affect rehabilitation workload in a National Team during an elite soccer event? An experience from the FIFA 2010 World Cup. J Sports Med Phys Fitness 2013;53:192-197.

Ekstrand J, Hägglund M, Waldén M. Epidemiology of muscle injuries in professional football (soccer). Am J Sports Med 2011;39:1226-1232.

Eom J, Rhee MH, Kim LJ. Abdominal muscle activity according to knee joint angle during sit-to-stand. J Phys Ther Sci 2016;28:1849-1851.

Floyd WF, Silver PH. Electromyographic study of patterns of activity of the anterior abdominal wall muscles in man. J Anat 1950;84:132-145.

Granata KP, Marras WS. Cost-benefit of muscle cocontraction in protecting against spinal instability. Spine (Phila Pa 1976) 2000;25:1398-1404.

Guilhem G, Giroux C, Couturier A, Maffiuletti NA. Validity of trunk extensor and flexor torque measurements using isokinetic dynamometry. J Electromyogr Kinesiol 2014;24:986-993.

Hermens HJ, Freriks B, Disselhorst-Klug C, Rau G. Development of recommendations for SEMG sensors and sensor placement procedures. J Electromyogr Kinesiol 2000;10:361-374. 
Higashihara A, Ono T, Kubota J, Fukubayashi T. Differences in the electromyographic activity of the hamstring muscles during maximal eccentric knee flexion. Eur J Appl Physiol 2010;108:355-362.

Iga J, Fruer CS, Deighan M, Croix MD, James DV. 'Nordic' hamstrings exercise-engagement characteristics and training responses. Int J Sports Med 2012;33:1000-1004.

Jenkins DB, Hollinshead WH. Hollinshead's functional anatomy of the limbs and back. 7th ed. Philadelphia (PA): WB Saunders; 1998.

Jull GA, Richardson CA. Rehabilitation of active stabilization of the lumbar spine. In: Twomey LT, Taylor JR, editors. Physical therapy of the low back. 2nd ed. New York: Churchill Livingston; 1994. p. 251-271.

Kim YR, Yoo WG. Effects of trajectory exercise using a laser pointer on electromyographic activities of the gluteus maximus and erector spinae during bridging exercises. J Phys Ther Sci 2016;28:632-634.

Koulouris G, Connell D. Evaluation of the hamstring muscle complex following acute injury. Skeletal Radiol 2003;32:582-589.

Kuitunen S, Komi PV, Kyröläinen H. Knee and ankle joint stiffness in sprint running. Med Sci Sports Exerc 2002;34:166-173.

Leinonen V, Kankaanpää M, Airaksinen O, Hänninen O. Back and hip extensor activities during trunk flexion/extension: effects of low back pain and rehabilitation. Arch Phys Med Rehabil 2000;81:32-37.

Mjølsnes R, Arnason A, Østhagen T, Raastad T, Bahr R. A 10-week randomized trial comparing eccentric vs. concentric hamstring strength training in well-trained soccer players. Scand J Med Sci Sports 2004;14: 311-317.

Murphy JC, O'Malley E, Gissane C, Blake C. Incidence of injury in Gaelic football: a 4-year prospective study. Am J Sports Med 2012;40:21132120.

Nelson-Wong E, Alex B, Csepe D, Lancaster D, Callaghan JP. Altered muscle recruitment during extension from trunk flexion in low back pain developers. Clin Biomech (Bristol, Avon) 2012;27:994-998.

Orchard JW, Seward H, Orchard JJ. Results of 2 decades of injury surveillance and public release of data in the Australian Football League. Am J Sports Med 2013;41:734-741.

Sado N, Yoshioka SH, Fukashiro S. Mechanism of the maintenance of sagittal trunk posture in maximal sprint running. Jpn J Biomech Sports Exerc 2016;20:56-64.

Sahrmann SA. Diagnosis and treatment of movement impairment syndromes. St. Louis (MO): Mosby; 2002.

Schmitt B, Tim T, McHugh M. Hamstring injury rehabilitation and pre- vention of reinjury using lengthened state eccentric training: a new concept. Int J Sports Phys Ther 2012;7:333-341.

Sherry MA, Best TM. A comparison of 2 rehabilitation programs in the treatment of acute hamstring strains. J Orthop Sports Phys Ther 2004; 34:116-125.

Snijders CJ, Ribbers MT, de Bakker HV, Stoeckart R, Stam HJ. EMG recordings of abdominal and back muscles in various standing postures: validation of a biomechanical model on sacroiliac joint stability. J Electromyogr Kinesiol 1998;8:205-214.

Snijders CJ, Vleeming A, Stoekart R, Mens JM, Kleinrensink GJ. Biomechanical modeling of sacroiliac joint stability in different postures. Spine: State Art Rev 1995;9:419-432.

Tateuchi H, Taniguchi M, Mori N, Ichihashi N. Balance of hip and trunk muscle activity is associated with increased anterior pelvic tilt during prone hip extension. J Electromyogr Kinesiol 2012;22:391-397.

Thelen DG, Chumanov ES, Hoerth DM, Best TM, Swanson SC, Li L, Young $\mathrm{M}$, Heiderscheit BC. Hamstring muscle kinematics during treadmill sprinting. Med Sci Sports Exerc 2005;37:108-114.

Thorborg K. Why hamstring eccentrics are hamstring essentials. Br J Sports Med 2012;46:463-465.

Vleeming A, Snijders CJ, Stoeckart R, Mens JM. The role of the sacroiliac joints in the coupling between spine, pelvis, legs and arms. In: Vleeming A, Mooney V, Snijders CJ, Dornan TA, Stoeckhart R, editors. Movement, stability and low back pain. New York: Churchill Livingstone; 1997. p. 53-71.

Willson JD, Dougherty CP, Ireland ML, Davis IM. Core stability and its relationship to lower extremity function and injury. J Am Acad Orthop Surg 2005;13:316-325.

Wohlfahrt D, Jull G, Richardson C. The relationship between the dynamic and static function of abdominal muscles. Aust J Physiother 1993;39:913.

Woodley SJ, Mercer SR. Hamstring muscles: architecture and innervation. Cells Tissues Organs 2005;179:125-141.

Woods C, Hawkins RD, Maltby S, Hulse M, Thomas A, Hodson A; Football Association Medical Research Programme. The Football Association Medical Research Programme: an audit of injuries in professional football--analysis of hamstring injuries. Br J Sports Med 2004;38:36-41.

Yeung SS, Suen AM, Yeung EW. A prospective cohort study of hamstring injuries in competitive sprinters: preseason muscle imbalance as a possible risk factor. Br J Sports Med 2009;43:589-594. 